\title{
The Sound Field Construction of Dance Hall
}

\author{
Hongbo HU \\ Department of Physics and Electrical Engineering, Zunyi Normal College, Gui Zhou, Zunyi 563002
}

Keywords: Dance hall, Sound filed, Reverberation time, Reverberation degree, Absorptive coefficient

\begin{abstract}
With the improvement of living standard of people in China, the degree of people's desire towards spiritual life is becoming higher and higher, and the dance hall has become one of the preferred place for recreation. Although most of the dance halls have good hard wares, the audio effect is not satisfying which is related with the ignorance of acoustic environment. If the distribution of sound field is irregular in the hall, and the reverberation time is over-long or over-short which will affect the musical sense of beauty. So this paper makes a detailed description of the methods of creating the sound field of dance hall.
\end{abstract}

\section{The demands and management of the dance hall room}

The demands of the dance hall room. The distinguished characteristics which are different from the general theatre and halls include the following three aspects: firstly, it has a big dancing floor with smooth surface which is a strong sound reflection surface. Secondly, at the top of the dance hall, the ceiling has a lamp bracket which possesses the majority of the art lighting, performance lighting, sound, video and other equipments. Thirdly, the dancing floor and the dancing stage are in the same space which has great sound volume and the sound level can achieve at $95 \mathrm{db}$. In addition, actors and singers often go into the dancing floor with the acoustic device which makes the acoustic amplification and the received sound mix together. And it can lead to whistler, so the sound field condition of the dance hall is very complicated. The scale of length, width and height is the direct factor which can make an effect on the quality of the sound field. When the scale is suitable, the resonance frequency will be well-distributed. Generally, the most favorable scale is the "gold scale" and that is $0.618: 1: 1.618$.

The management of sound insulation and sound absorption. In order to create a good sound field, people should take the sound insulation into consideration which may refer to the sound insulation between the building and the outside, and the sound insulation among all the rooms of the building. The rooms of the dance hall have its own unique acoustic characteristics. The building material, the size and shape of the space, the inside decoration and the distribution of equipment all make an effect on the sound, so the timbre may be active and lively as well as oppressive and dull. If there are too many parallel surface, and the sound make a round trip reflection on the relative parallel walls which have strong reflection in the hall, so the sound energy is difficult to be decreased which will generate sound vibration and rhythmic pulse-liking sound as "beat" and "drone". So the decoration of the wall should avoid concave and the formation of sound coalescence which may destroy the tone quality. When there are much soft material like curtain and carpet which can absorb most of the sound, so the sound will be dull, lifeless and lack of low pitch as the result of lacking of reflected wave. So the scale of sound absorption and reflection must be appropriate and should make management according to the actual condition.

\section{The reverberation regulation of the dance hall}

Reverberation is the result of accumulated continuous sound reflection by the surface in the hall. Reverberation can increase $15 \mathrm{db}$ of the sound as well as decrease the articulation of language. With the reverberation, the music can be leisure and delighted in the dance hall. If the reverberation time is over-long, the sound will be mixed; on the contrary, the sound will be dry, dead, and unattractive. Reverberation time is the standard to describe the reverberation effect. There is mathematic relation 
between reverberation time and inside sound absorption, and that is the famous Sabin Formula in architecture: $\mathrm{t}=0.161 \mathrm{v} /(\mathrm{s} * \mathrm{a})$ in which the letter $\mathrm{t}$ represents the reverberation time, $\mathrm{v}$ represents the room volume, s represents the total superficial area of the walls and a represent the average sound absorption coefficient of the room surface. According to the formula, it is clear that the bigger the room volume is, the longer the reverberation time is, and the bigger the average sound absorption coefficient is, the shorter the reverberation time is. The vast space like the gymnasium, if people do not make sound absorption management, the reverberation will be very long which will have a great effect on the articulation of language. As the inside sound absorption is related to frequency, so different frequency may have different reverberation time. The suitable reverberation time make a good performance of audio system and the sound is full, smooth and attractive, pleased. According to the study, the satisfying reverberation time is around 1.8 second to 2.1 second. The space and surround feeling resulting from reverberation has a great effect on the sound. In order to adapt to the different function of the dance hall, the most suitable reverberation time should make adjustment according to different sound source condition.

The intensity of reverberation and frequency is direct proportion. The sound in the same sound field, the higher the frequency is, the greater the damage is in broadcasting. So if the sound frequency is relative high, the reverberation intensity should be made greater. For example, when the female singer is performing, if people want to make reverberation management on her voice, the degree of reverberation intensity should be bigger; as the male voice is higher then the female voice with eight degrees, the reverberation intensity of male is lower than the female's. If the male voice is adjusted relative high, it is easy to be turbid and unclear.

The lower reverberation intensity of lively songs. In the dance hall, there are one or two thousand songs provided for people. Among them, many are lively and happily, for example, the lively rhythm Indian song" Jili ", and the Romanian song "Jingting Girl", the intermittent time is very short. If the reverberation intensity is high, the words of the song will be blurred and indistinct. If the song is with low rhythm, for example, the lyric songs like" Yesterday Once More", " Thinking of You" which are leisure, deep and with many long syllables. If the long syllables do not have reverberation, they will be void, tasteless and dry. So the reverberation intensity should be higher and the emotional degree will be deeper.

The core purpose of vocal songs is the beauty of the rhythm and the reverberation intensity should be lower. The reason is that most of the people who are good at bel canto performance have specialized sound production training, so their timbre is generally good. In order to represent their own characteristics, there is no need to make a big degree of reverberation management. The reverberation intensity of national songs should not be too high, as the aims of national songs are their style and taste. So the low reverberation intensity can retain the taste and local color of national songs. While the popular songs are aim at their emotion, the process on the sound should be exaggerated and the reverberation intensity can have a higher degree, and it can express the emotion more abundant.

For the professional singers, the management range of reverberation intensity should be small. In the dance hall, usually there are some professional singers who come to be the guest or the host. As the throat condition of the professional singers is excellent, in order to keep their own timbre characteristics, the management range should be small. If there is one amateur singer and his throat condition is relative poor, the management range should be bigger. That is to put more powder on his timbre for covering his shortcomings. So for amateur singers, the reverberation intensity should be higher.

When the dance hall is full, for example in some festival like Christmas, Mid-Autumn and so on, the guests are nearly full of the hall every time. The number of people is larger, the amount of absorption on sound is larger and the damage of the sound in the sound field is larger, especially the high frequency reverberation. And then the reverberation intensity should be larger for keeping sufficient thickness and fullness.

If the dance hall is in free time, although the reverberation intensity is relatively small, the sound still sounds thick and full. As the number of people is smaller, the damage of reverberation is less. So when the dance hall is in open-field, the reverberation intensity should be small. 


\section{The application of electroacoustic system}

When the reverberation time is adjusted well, it is time to regulate the degree of reverberation intensity. If the reverberation time is over-long, but the reverberation is small, people can not aware the existence of reverberation. In order to get good sound field effect and builds vivid fidelity of encirclement and ambiance, the application of electroacoustic system, which usually refer to the application of stereo and encirclement, is some kind of general method.

In order to get the optimum replaying effect, the arrangement of the loudspeaker box is very important. The main loudspeaker box is composed of the ultralow loudspeaker and the alt loudspeaker box which is set on the both the sides of the stage. The assisted loudspeaker box, which can be set at the rear of the dance hall or on the roof according to the condition of the dance hall, or be set with the loudspeaker box bracket, which can make the sound reflection outside and the reverberation lively and attractive, is the full range loudspeaker box.

In dancing disco, the power of the loudspeaker is insufficient and in singing, the loudspeaker box is closed or very low which can satisfy the different demands of different condition. The arrangement of loudspeaker box of disco hall should obey the following rules:

There are two to four ultralow loudspeaker boxes at the two sides of the stage. The loudspeaker box which can be sloped foldback loudspeaker box can be set around the hall. The direction of the loudspeaker box is centralized at the centre of the hall which can form the impinging tone and cause the sound pressure reach at 110 to $120 \mathrm{db}$. The sound pressure around the seats is under $95 \mathrm{db}$ which can guarantee the people not dancing have a rest and chat. The low pitch loudspeaker box is set at the two sides of the terrace, because the directionality of low pitch is not strong and the sound can be full of the hall which can keep the sound pressure at a very high level.

In one word, if the dance hall can adopt the scientific method and reasonable regulation according to different time period, sound effects and make the equipment at the optimum condition, the sound field of the dance hall can be gradually well-distributed and get the optimum sound effects.

\section{References}

[1] Cheng Yong. Audio technology and equipment, 1997,11. Zhejiang University Press.

[2] Zhang Yizhong. Practical audio-visual guides, 1995. Beijing: Publishing House of Electronics Industry.

[3] Zou Weisheng. A handbook of tuner in the dance hall, 2002. Beijing: China Light Industry Press.

[4] Han Guangxing. The theoretical configuration and repair of audio and home theater. Beijing: Publishing House of Electronics Industry.

[5] Zhi Le. The debugging and repair of audio technology and equipment, 2000,7. Higher Education Press.

[6] Nie Guanglin. Audio equipment theory and repair, 1996,6, p167. Southwestern Normal University press.

[7] Pan Ruihua. The special and auxiliary circuit of the audio, 2000,1. China Light Industry Press.

[8] Wang Junwei. The audio equipment theory and repaired techniques, 1995,6. Higher Education Press.

[9] Jin Jicai. The practical handbook of modern audio techniques, 2000,6. Anhui Science and Technology Press. 